fossil organisms. It is pointed out that areas of bogland (Sumpflachmoor) and peat may arise even in tropical conditions, moisture and low-lying land being the real necessities, and Wegener is cited as regarding all the great coal-basins as formed in a zone of equatorial rains. The important question of annual rings in wood, discussed recently in Deecke's "Paläophytologie" (see NAture, September I6, p. 375), receives careful consideration, and the author concludes that these rings cannot be used by themselves as elucidating climatic conditions. Dr. Eckardt supports the view that seasonal changes of temperature have been felt in polar regions even when the climate was warmer over the whole earth; but at certain periods mild subpolar winters have been associated with summers much hotter than those of the present day.

A. Handlirsch is interestingly quoted as showing how the length of the anterior wing in insects may be used as an indication of prevalent temperature since it increases at the present day from an average of $7 \mathrm{~mm}$. in central Europe to $16 \mathrm{~mm}$. in the tropics. The length in Lower and Middle Carboniferous strata in our latitudes is as much as $5 \mathrm{I} \mathrm{mm}$., but decreases in Upper Carboniferous and Permian times to 20 or to I7 $\mathrm{mm}$. Little that bears on his subject has escaped Dr. Eckardt, and the correlation of scattered scientific observations, in the hope of solving problems, is aptly illustrated in his concluding sentence, where he quotes Eckholm as showing that great importance must be attached to the obliquity of the ecliptic in explaining the post-Glacial distribution of the hazelnut in Scandinavia.

Dr. Eckardt points out that at the present day the relative distribution of land and water has an influence on climate only about a third or a quarter as important as that of latitude. Prof. E. W. Berry, however, in a paper on a possible explanation of Upper Eocene climates (Proc. Amer. Phil. Soc., vol. $6 \mathrm{I}, \mathrm{p} . \mathrm{I}, \mathrm{I922}$ ), urges that a prevalence of lowlying land as against mountain areas, and an enlargement of oceanic areas, allowing of free circulation from broad equatorial basins to the poles, was a sufficing cause of the warmer, though still zonal, conditions revealed by Eocene vegetable remains. The Upper Eocene hazel, for example, came no farther south in Eocene times than lat. $45^{\circ}$, because the Atlantic basin resembled in breadth that of the present Pacific Ocean. The author even looks back to the views of Lyell, and suggests that "the distribution and altitude of the land and sea" may have accounted for the glacial epochs.

A. Brockmann-Jerosch, who is much quoted by Dr. Eckardt, has recently suggested that glacial conditions in Switzerland were favoured by an oceanic climate and a copious rainfall ("Die Vegetation des Diluviums in der Schweiz," Conférences de la Soc. Helvétique des Sci. nat., I920, p. 73). Perhaps the proximity of the mountains in this area removed one of the factors relied on by Berry. There is clearly much philosophical discussion still before us in palæoclimatology.

G. A. J. C.

\title{
Studies on Phytophthoras.
}

$\mathrm{I}$ the Mededeelingen v. d. Landbourwhoogeschool, Wageningen, xxiv., No. 4, I922, Miss de Bruyn publishes (in English with a Dutch summary) a paper entitled "The saprophytic life of Phytophthora in the soil." After reviewing the literature pertaining to fourteen species of the genus in relation to the question of their capacity for life as saprophytes in the soil, Miss de Bruyn describes her own work on the cultivation of the three species, $P$. Syringe, $P$. erythroseptica and $P$. infestans, in soils of different types. Most of the experiments were carried out with soil which had previously been sterilised, and details of the growth in this medium are given in each case.

The general conclusion reached is that Phytophthoras are not such obligate parasites as was formerly supposed, and it is claimed that the experiments carried out prove that each of the species mentioned can actually live and grow in the soil. Cultures on sterilised soil as well as on other media were exposed out of doors to rather severe frost for several days, and it was found that $P$. Syringe and $P$. erythroseptica survived such treatment. So far as the cultures in soil are concerned, however, it would appear that such survival may have been due to the presence of oospores. In the case of $P$. infestans (the oospores of which are still unknown in Nature) the results of exposure to similar conditions were not concordant, and the question as to whether this species can overwinter in the soil is regarded as unsolved. It was found, however, that when growing on sterile raw potato slices, $P$. infestans survived a temperature of $-9^{\circ} \mathrm{C}$., although at this low temperature the potato slices themselves were blackened.

Attempts were made to cultivate $P$. Syring $e$ and $P$. erythroseptica in non-sterilised soil, but the results do not appear to have been very satisfactory. It seems clear that further and more critical work will have to be carried out before it can be accepted as convincingly established that these two fungi are really capable of sustained growth and development in ordinary soil. No information is given as to whether $P$. infestans was found to live and grow in ordinary unsterilised soil; and speculation as to whether the survival of this fungus in the soil from season to season may account for primary outbreaks of potato blight seems therefore altogether premature.

Another recent contribution to our knowledge of this fungus is contained in a doctorate thesis presented to the University of Utrecht by Miss M. P. Löhnis, entitled "Onderzoek over Phytophthora infestans (Mont.) de By. op de aardappelplant." (Wageningen, H. Veenman, I922.) An account of pure culture work with various media is given; immature oogonia and oospores were found twice in cultures on raw potato and Quaker Oat agar.

Experiments on the manner in which infection of the potato occurs are described, and in discussing the question of the propagation of the blight from season to season it is recorded that on five occasions a diseased tuber was found before any infection of the foliage was apparent. It is suggested that the fungus may perhaps subsist in the soil, but this point is not yet regarded as definitely established. Other matters dealt with are the influence of the stage of development of the plant on its susceptibility to infection, the mode of entry into the tubers and growth of the fungus in the subterranean parts of the plant, the formation of wound cork and varietal resistance to blight. The thesis is provided with a summary in English, and a more detailed abstract of it will be found in the Review of Applied Mycology, I. 8. Aug. I922, p. 253 . 